UDC 811.111

DOI: $10.17223 / 24109266 / 8 / 4$

\title{
GENERALIZED MEANING OF GRAMMATICAL MODEL IN SPEECH
}

\author{
T.V. Khvesko, N.Yu. Basueva \\ Tyumen State University (Tyumen, Russian Federation) \\ E-mail:khvesko@inbox.ru; eflecturer@mail.ru
}

\begin{abstract}
The aim of the article is to show the semantic aspects of grammar modeling while applying the cognitive linguistic approach. The authors analize the correlation of universality of the Complex Object model and its specific features in speech. The referent embodiment is realized through its mental activity (perception, assessment, causation, and willingness). Analyzing the Complex Object structures in communication the authors come to the conclusion that blending is realized with the help of spatial and temporal markers: the process of subject causative effect and the object predicted result; the process of sensory perception and the (un)real picture of the developing event. Duration in time or moving in space to completeness processes are represented in the standard grammatical model and vary due to verbalization of thought in speech.
\end{abstract}

Keywords: generalization; cognitive linguistics; grammar modeling; spatial and temporal markers; speech.

\section{Introduction}

The central idea of cognitive grammar is that the lexicon, morphology and syntax form a unity, not decay naturally into disjoint classes, while showing a great variety in regard to the level of generality and structural complexity.

Generalization is reflected in the theoretical foundations of speech/thought activity in L.S. Vygotsky work, where the main idea is the collective consciousness, the need to put each notion to a certain class of the well-known group of phenomena, which certainly requires generalization. Higher human forms of psychological communication are only possible thanks to the fact that a person reflects reality by the way of thinking collectively [1].

Some models have a generalized grammatical meaning of the "subject in the state of perception and evaluation of the world". This standard model is called Complex Obect. The fact that the grammatical model is a generalized form of thought was proved by professor Helen Kubryakova, the founder of the cognitive science approach in Russia. "The speaker's subjective image of the objective world and the individual view of the world are reflected through the collective memory of the world" [2].

Within this context of assumptions on subjectivity and the collective consciousness the purpose of the present article is to interpret the semantic 
aspects of grammatical modeling from the cognitive linguistics view. More specifically this paper aims to show the relation of the universal (generalized) aspects of grammatical constructions and manifestation of specific features in the structure of the English sentence (Complex Object), reflecting the embodiment of the referent in the mental spaces (perception, causation, willingness or assessment), which are complemented by the expression of spatial and temporal relations.

The idea takes shape thanks to the cognitive and linguistic processes, in which sensory data are converted into a mental representation. Nickolay Boldyrev stresses the idea that the diversity of knowledge determines different ways for the formation of grammatical concepts in the human mind: on the basis of sensory experience, e.g. as a result of the surrounding world perception (seeing, feeling or hearing) and on the basis of mental activity (as a result of arguments, inferences, conclusions) [3]. Consequently, the linguistic form and the grammatical model are a reflection of cognitive structures in human consciousness, thinking and cognition. Thus, cognition is directly associated with a definite language. According to Valery Demyankov any statement consists of two components: the intuitive (generalized) and rational (individual), which manifest itself in the forms of language [4]. This idea can be supported by George Lakoff thought that a set of universal models in grammar is limited and can be reduced to perception, estimation or effect: "children first learn literal see as in See doggie and See Daddy. Then they learn cases which he referred to as "conflations", where the domains of seeing and knowing are co-active, that is, where both are at issue, as in sentences like: See Daddy come in. See what I spilled. Finally, children learn pure metaphorical cases like: See what I mean" [5].

The goal of cognitive grammar, according to R. Langacker, is to characterize the psychological structures that make up the human language ability, the ability to master the language conventionally established USES. The author refers his approach to language structure as a usage - based one. The author states that he prefers the cognitive and linguistic adequacy of the concept rather than formal purity of generative grammars, which is based on the distortion and impoverishment of the content aspect [6].

In contrast to the concept of generative grammar R. Langacker puts forward and justifies the view of the language system as vast and largely redundant array of units not amenable to algorithmic calculation. Under certain unit the author understands perfectly mastered structure or cognitive pattern. Defining language grammar as an organized inventory of conventional linguistic units (structured inventory of conventional linguistic units), the author emphasizes that the grammar is not generating. Inventory is arranged so that one unit can serve the parts of other constituents. The process of building the language structures by a speaker is represented as sequential assembly of the inventory resources, according to the cognitive patterns (also 
included in the inventory). In this case the result of this assembly is sometimes explicitly contrary to what might be "calculated" on the basis of the actual content of the language units, because a speaker in the process of building the voice structures guided not only by linguistic convention, but also the context of understanding, communicative goals, general knowledge [7].

\section{Investigation}

Having analyzed all the aforementioned views we decided to study mental spaces in correlation with language units. The cognitive assessment activity, according to Olga Iriskhanova's view, is a complex process of integration structures of personal and social knowledge that come into regular one-to-reverse relations, on the basis of conceptual integration and metaphorical model correlating in order to form the evaluation metaconsept of the secondary plan. The result of integration is based on a comparison of parameters. New knowledge will be fixed in a grammar structure, which will receive a secondary interpretation [8]. In particular, the assessment of "the practical value of the object" refers to a basic level of categorization and is one of the most important categories in the evaluation of the objects of reality. The subject of evaluation operates mainly by personal knowledge in the process of nomination. The primary knowledge is subjected to a secondary interpretation followed by the formation of new assessment meaning, verbalized by the language model e.g.:

'I really do not know what you expect me to do', he said (G. Durrel).

...I have more than once regretted bitterly, over flouring, superfluous words, and feared I had said more than he expected me to say... (Sh. Bronte).

These models are characterized by the structural and semantic standardization, a high degree of stability, where the weakening of the lexical meaning of the verb expect is accompanied by the meaning of assessment on the metonymic or metaphorical basis.

There is a primary level of thinking, where the language cognition is considered as an interpretation of the objective reality images in consciousness. In the process of reality perception both universal and individual cognitive processes are used. R. Langacker considers it necessary to postulate a number of basic areas (basic domains) as cognitively irreducible representations, among which the author mentions our experience of space and time, as well as the color scheme, the frequency range, temperature scale, the area of aste sensations, etc. - all this according to perceptual abilities of the human body [7].

G. Fauconnier considers mental spaces to be the cognitive structures that exist only in the minds of the interlocutors. According to his theory, there are two types of mental spaces: basic space is used to describe reality (it is clear both interlocutors), and mental spaces that go beyond reality by 
appealing to possible worlds, along with the expression of spatial parameters, fictitious structures, games, etc. [9].

Some embodiments of the referent dominated that testifies their primacy dealing with in the human mind. The embodiment is considered to be the human activity on the construction of mental representations of the knowable referent [10]. E. Rosh concept establishes the connections between the world and the man, which lies at the basis of the experience of human interaction with the surrounding reality: "The embodiment is of dual nature: it combines the physical, material as the evidence of our experience and our own body as a receptacle of cognitive mechanisms for the formation of this experience" [11]. The semantics of the verb indicates that the referent embodiment takes place with the participation of one of several areas: motor, sensory-sensitive (audio, visual) and modus. Sensory perception area is manifested by the models, where sensory perception verbs (hear, see, watch, find) in conjunction with the ing-form of the object perceived action (coming, wheezing, marching) occur as an indicator of a process, developing in the space, e.g.:

Once in the night we went to sleep and when I woke she was not there, but I heard her coming along the hall and the door opened and she came back to the bed and said it was all right she had been downstairs and they were all asleep (E. Hemingway).

Assembling sleepily in Michael's room we found him wheezing and gasping, the sweat running down his face (G. Durrel).

...Donne followed Malone, and Sweeting followed Donne; and more wine was ordered up from the cellar into the dinning-room (for though old Helstone child the inferior priesthood when he found them "carousing", as he called it, in their own tents...

Sometimes in the dark we heard the troops marching under the window and guns going past pulled by motor-tractors (E. Hemingway).

The combination of sensory perception verbs (hear, see, watch) with the infinitive form of the perceived object action (laugh, do, settle) shows, that the perceived effect is static and it has already been made, e.g.:

She laughed. It was the first time I had ever heard her laugh. I watched her face (E. Hemingway).

I have never seen you do anything myself (E. Hemingway).

I watched them settle on the ceiling (E. Hemingway).

I saw the major look at him and notice that he was drunk (E. Hemingway).

He watched his father stalk the choicest animals, his young eyes hard brown with excited interest (E. Hemingway).

A regiment went by in the road I watched them pass (E. Hemingway).

5 per cent of the young people stopped, were found to be in actual possession of drugs (Morning Star. September 29, 1972). 
He was seen (as a statesman who needed time) to complete what he had begun (New Times 47. November 1, 1972).

We consider that mental diagram representation of the processes that occur in the human body is based on the spatial parameters of the referent embodiment and shows the process of perception of the object or the completeness of the object action [12]. Modus zone of the referent embodiment is manifested by expression of will, e.g.: 1980).

...We knew he did not want us to think that at all (The Times. Aug.,

'Priest not happy. Priest wants Austrians to win the war', the captain said (E. Hemingway).

I do not. I do not want anyone else to touch you. I'm silly (E. Hemingway).

"I do not want you to drop the department in again" (Morning Star. August 2, 1979).

You want us to stay here or can we look around? (E. Hemingway).

The willingness develops to a certain point, that is represented in the linguistic form of the infinitive, where the particle to has the meaning of the limitation, e.g.:

Which only serves to make the point that Mr. Biffen and his colleagues are up to things he very much does not want us to know about (Morning Star. July 26, 1979).

- Would not you like me to have some more exalted rank?

- No, darling. I only want you to have enough rank so that we're admitted to the better restaurants (E. Hemingway).

The basic thesis of the authors of cognitive theories is the belief that the individual's behavior is determined by knowledge and ideas. The human ideas about the world are projected in behavior: what a person says and how he does it, depends ultimately not only on the needs of fixed, deep and eternal aspirations, but also on genetic heredity. G. Lakoff, talking about mental cognitions, asked... how it is possible for all human beings to have the same primitive image-schemas, which can be combined differently in different languages [5]. The models associated with the processes of human interpretation of the world and a man in this world are the constructions of the causative prototype. Ludmila Furs notes that syntactic processes of the causative meanings are complex and require the definite criteria for unambiguous interpretation of causative effect. The existing heterogenety in the field of constructions with lexical meaning of causation can be eliminated on the basis of verbalization ways differentiation according to the result obtained "actuality/potentiality". Actualization of causation result, which is understood as initiated intention, successfully realized effect on causation object can be attributed to the category of causative constructions. The constructions which do not give a clear interpretation of the result differ from proto- 
type category causative constructions, e.g.: She ordered me to stay awake [13]. The nature of causation (actual or potential) can be determined only on the basis of the context. L. Talmy separates a group of verbs having a linguistic code of causative effect according to the marker of "realization of the action" [14]. The semantics of the verbs induce, cause, get, have, make, force includes the marker "realization of the action" while the semantics of verbs persuade, convince, decide does not. The presence of the language mechanisms of causativity meaning differentiation indicates the relevance of speech variations, e.g.:

They made him take off his coat and waistcoat.

It might be that an admirer of his had pestered him to introduce me to her or that an American editor, in London for a few days, has desired Roy to put me in touch with him (S. Maugham).

The following models show that the action expressed by the infinitive is potential, e.g.:

I never allow outsiders to come to rehearsals, but as you are our accountant you almost belong to the theatre, and I would not mind making an exception in your favour if it would amuse you to come (S. Maugham).

I wonder if we could persude you to come and eat a chop with us (S. Maugham).

The verbs of speaking (verbal actions) are used in the case of potential effect, e.g.:

O'Farrell said wayward soccer genius Best would have been asked to attend the board meeting... (Morning Star. December 6, 1972).

National guardsmen have been ordered to impose a curfew on the University... (Morning Star. April 22, 1972).

The New Nicaraguan government has declared a national emergency empowering authorities to recruit Labour without payment, commandeer private vehicles and requisition private property for a temporary period (Morning Star. July 26, 1979).

\section{Conclusion}

The aim of the article was to show the semantic aspects of grammar modeling applying the cognitive linguistic approach, to show the generalization of the Complex Object model and its variants in speech. The referent embodiment is realized through its mental activity (perception, assessment, causation, and willingness). Analyzing the Complex Object structures in speech the authors came to the conclusion that blending is realized due to the spatial and temporal markers: the process of subject causative effect and the object predicted result; the process of sensory perception and the (un)real picture of the developing event and the process of assessment of the object. The perception of an object is presented through the prism of spatial and temporal characteristics (duration or completion of the process of perception). 
Blending is not predictable solely from the structure of the inputs. Rather, they are highly motivated by such structure, in harmony with independently available background and context. The variability of spatial and temporal relations takes place in the Complex Object structure. Application of such models in order to show duration in space and time or moving in space to completeness are represented by the standard grammatical model due to verbalization of thought in speech.

\section{References}

1. Vygotsky, L.S. (1982). Thinking and Speech. Collection of works. V. Moscow: Progress. p. 16.

2. Kubryakova, E.S. (2008). Nominative aspect of Speech Activity. Moscow: Izdatelstvo LKI.

3. Boldyrev, N.N. (2014). Cognitive Semantics. Introduction to Cognitive Linguistics: course of lectures. 4. Tambov: Izdatelski Dom TSU after G.R. Derzhavin. pp. 19-41.

4. Demyankov, V.Z. (1994). Cognitive Linguistics as a kind of Interpretation Approach. Voprosy Yazykoznanya. 4. pp. 17-33.

5. Lakoff, G. (2001). How the Science of Mind Changes Our Understanding of the World. Embodied Mind, Embodied Philosophy. The Gifford Lectures. University of Glasgow. pp. 3-20.

6. Langaker, R. (1988). Usage-based Model. Topics in Cognitive Linguistics. Amsterdam, Philadelphia. pp. 127-161.

7. Langacker, R. (1991). Foundations of cognitive grammar. Vol. 2: Descriptive application. Stanford, CA: Stanford University Press. pp. 17-34.

8. Iriskhanova, O.K. (2001). About the Theory of Conceptual Integration. Izvestya of Academy of Science. Literature and Arts Seria. 60 (3). pp. 44-49.

9. Fauconnier, G., and Turner, M. (1998). Conceptual Integration Networks. Cognitive Science. 22 (2). pp. 133-187.

10. Kiose, M.I. (2014). About some features of Indirect Nomination Referent Embodiment. Voprosy of Cognitive linguistics. 3. pp. 65-73.

11. Rosch, E. (1975). Cognitive representation of semantic categories. Journal of Experimental Psycology: General. 104. pp. 192-233.

12. Khvesko, T.V. (2008). Linguistic Reasons of Apellative and Onomastic Lexicon Forming. Voprosy of Cognitive Linguistics. 3. pp. 70-76.

13. Furs, L.A. (2013). Interpretation of Causativnosti in Syntax. Cognitive Investigation of Language. XY. pp. 174-182.

14. Talmy, L. (2000). Toward a Cognitive Semantics. Vol. 1: Concept structuring Systems. Cambridge, Massachusetts: The MIT Press.

Resived 02.09.2016.

\section{Information about the authors}

Khvesko Tamara - Doctor of Phylology, professor of the Department of Foreign languages and Intercultural Comunication of the Tyumen State University (Tyumen, Russian Federation). E-mail: khvesko@inbox.ru

Basueva Nadezhda - master of sociology, professor assistant of the Department of Foreign languages and Intercultural Comunication of the Tyumen State University (Tyumen, Russian Federation). E-mail: eflecturer@mail.ru 